\title{
A prospective study assessing the pattern of response of local disease at DCE-MRI after salvage radiotherapy for prostate cancer
}

\author{
Marta Bottero \\ IRCCS Regina Elena National Cancer Institute \\ Adriana Faiella \\ IRCCS Regina Elena National Cancer Institute \\ Diana Giannarelli \\ IRCCS Regina Elena National Cancer Institute \\ Alessia Farneti \\ IRCCS Regina Elena National Cancer Institute \\ Pasqualina D'Urso \\ IRCCS Regina Elena National Cancer Institute \\ Luca Bertini \\ IRCCS Regina Elena National Cancer Institute \\ Valeria Landoni \\ IRCCS Regina Elena National Cancer Institute

\section{Patrizia Vici} \\ IRCCS Regina Elena National Cancer Institute \\ Giuseppe Sanguineti ( $\sim$ giuseppe.sanguineti@ifo.it) \\ IRCCS Regina Elena National Cancer Institute
}

\section{Research Article}

Keywords: prostate cancer, salvage radiotherapy, dynamic contrast enhancement magnetic resonance imaging, local failure

Posted Date: February 16th, 2022

DOI: https://doi.org/10.21203/rs.3.rs-1350793/v1

License: (c) (1) This work is licensed under a Creative Commons Attribution 4.0 International License.

Read Full License 


\section{Abstract}

Background: To assess the pattern of response of presumed local lesions at dynamic contrast enhancement magnetic resonance imaging (DCE-MRI) after salvage radiotherapy (sRT).

Methods: This is a prospective study conducted at a single Institution accruing patients with one or more local failures at DCE-MRI after radical prostatectomy between August 2017 and June 2020. Patients underwent exclusive sRT delivering 66-69 Gy and 73.5 Gy in 30 fractions to the whole prostatic fossa and to the local failure(s) seen at DCE-MRI, respectively.

Patients were offered DCE-MRI at 3 month-intervals after SRT until complete dis-appearance (CR) of the lesion(s) or up to a maximum of 4 re-evaluations.

Results: 62 patients with 72 nodules were enrolled. All patients underwent the $1^{\text {st }}$ re-evaluation, and 33 patients (53.2\%) showed a CR. The median time to CR was 4.7 months. Four patients did not undergo further testing before achieving a $\mathrm{CR}$ and even considering these patients as no responses, the vast majority (87.1\%, 95\% Cl: 78.5-94.4\%) of lesions would have completely disappeared by 12 months from the end of $\mathrm{SRT}$.

The volume of the lesion at pre-sRT DCE-MRI was an independent predictor of CR at the $1^{\text {st }}$ re-evaluation (OR: 0.076, 95\%Cl: 0.009-0.667; $p=0.020$ ) along with time elapsed from SRT (OR: 3.399, 95\% Cl: 1.1569.993, $p=0.026)$.

Conclusions: The present study documents the complete dis-appearance of the vast majority of local lesions after dose-escalated SRT though this requires several months after SRT; timing of CR is at least in part predictable based on the volume of the lesion.

Trial registration: Clinicaltrials.gov NCT04703543, registered July 15 2020, retrospectively registered, https://clinicaltrials.gov/ct2/show/NCT04703543.

\section{Background}

The proper evaluation of response to therapy is crucial in cancer treatment evolution and amelioration. Acknowledging the presence of residual disease after a local therapy helps to tailor treatment intent and its aggressiveness.

After exclusive salvage radiotherapy (sRT) for a presumed local failure following radical prostatectomy, about $30-40 \%$ of patients show further biochemical progression at 5 years (1-3). However, serum prostate specific antigen (PSA) measurement lacks spatial information and the pattern of failure of patients in this clinical scenario remains unclear for the majority of them (2-5). The paucity of data on the local response rate to SRT is partly due to the fact that none of the above studies requested a detailed imaging study of the prostatic fossa before SRT consistently with the recommendations (6) and the limitations of the imaging modalities (7) at the time these studies were undertaken. An exception is the SAKK trial, 
though MRI of the prostatic fossa was done in only about a third of the patients and multiparametric sequences were not required per protocol (1). If the prostatic fossa is not properly staged before sRT, response cannot be obviously assessed.

At our Institution multiparametric magnetic resonance is part of the restaging process for patients with a biochemical failure after radical prostatectomy (RP) and it is systematically performed in patients who are candidates for SRT (8). As part of a prospective study enrolling patients with a presumed local failure at restaging MRI and undergoing exclusive SRT (9), local response was assessed at regular intervals with dynamic contrast enhancement magnetic resonance imaging (DCE-MRI) during follow up, providing unique data on local response of prostate cancer to sRT.

\section{Materials/subjects And Methods}

The present prospective study was conducted at a single Institution between August 2017 and June 2020 (Clinicaltrials.gov NCT04703543). The study was approved by the Institutional Review Board (RS 946/17) and specific written informed consent was obtained by each patient before enrollment. Selection criteria as well as other methodological aspects of the study have been reported previously in details (9). In order to be eligible, patients had to have an history of localized prostate cancer treated with RP, followed by an undetectable $(<0.1 \mathrm{ng} / \mathrm{ml})$ PSA and a subsequent biochemical recurrence ( 2 consecutive PSA rises up to $0.2 \mathrm{ng} / \mathrm{ml}$ or higher). At restaging with DCE-MRI, all patients had to harbor a presumed local failure defined as an early/fast enhancing discrete lesion on DCE-MRI possibly with a T2W hyperintense lesion $(8,9)$. The location of each detected lesion was classified as per Connolly et al in perianastomotic, bladder neck and retrovesical (10).

All scans were obtained at our Institution and details can be found elsewhere (9).

All patients then underwent sRT, consisting in an intensity modulated approach to the whole prostatic bed to $66-69 \mathrm{~Gy}$ in 30 fractions. Presumed local failures at DCE-MRI were prescribed $73.5 \mathrm{~Gy}$ with a simultaneous integrated boost technique. The presumed site of local failure at DCE-MRI was outlined as clinical target volume (CTV) after co-registration to the planning computed tomography (11). The CTV was enlarged by an $8 \mathrm{~mm}$ isotropic margin to the planning target volume (PTV). When treated (9), the pelvic nodes (bilateral internal, external and common iliac lymph nodes as well as pre-sacral lymph nodes) were prescribed $54 \mathrm{~Gy}$ in 30 fractions. Details on treatment planning and delivery have been reported previously (8).

All patients were offered repeated DCE-MRI (rDCE-MRI) at our Institution as described above and interpreted by the same single observer (L.B.). Response was assessed exclusively on DCE sequences and defined with a qualitative method as it follows: complete response (CR) as the complete disappearance of the target lesion at DCE-MRI, partial response (PR) as any reduction of the size of the area/volume of early/fast enhancement, no response (NR) as no change in size/volume of the target lesion at DCE-MRI. 
The first rDCE-MRI was planned at 3 months after SRT completion. In patients without a complete response, imaging was repeated at 3-month intervals until complete dis-appearance or a maximum of 4 repeated scans. In case of complete response, no further scans were offered.

The endpoint of the study is the achievement of a CR at rDCE-MRI during the follow up. Therefore, responses were further dichotomized in $\mathrm{CR}$ and noCR, that includes both PR and NR. For patients with multiple local lesions, CR implied the complete disappearance of all lesions seen before SRT. The analysis was initially set for a complete database (no missing observations during the follow up). Unfortunately, some patients did not undergo all planned examinations. Therefore, the analysis has been carried in terms of both actual cumulative incidence (the number of new CRs divided by the total number of individuals at risk) and actuarial cumulative incidence using the Kaplan Meier estimate censoring for patients who did not undergo further testing at the date of last examination. Groups were compared with the chi-squared test, the Mann-Whitney rank test or the log-rank test when appropriate. For proportions, confidence intervals $(\mathrm{Cl})$ were computed with the Wilson score method without continuity correction.

Univariable/multivariable binary logistic regression analyses on CR were performed considering the Gleason Grade Grouping at RP (1-2 vs 3 vs 4-5), the PSA value at failure (continuum), the PSA doubling time at failure (continuum), the nodule volume at pre-sRT MRI (continuum), the number of failures at pre-sRT MRI (1 vs multiple), the time interval between RP and sRT (continuum), the time interval between the end of SRT and rDCE-MRI (continuum), the percent decrease of PSA at the $5^{\text {th }}$ week of SRT (continuum) and the location of the failure, anastomotic (yes vs no), in the bladder neck (yes vs no) and retrovesical (yes vs no). For patients with multiple lesions, the total volume was computed by adding up each nodule volume.

PSA recurrence after SRT was defined as a $0.2 \mathrm{ng} / \mathrm{ml}$ PSA rise above the nadir (12). Statistical significance was claimed for $p$ values $<0.05$. All statistical tests were performed using GraphPad (version 8.0.1, GraphPad Software Inc., San Diego, CA) and SPSS (version 25, IBM, Armonk, USA).

\section{Results}

\section{Patients and scans}

Sixty-two patients with 72 lesions were enrolled. Selected patient characteristics have been reported before in details (9) and are summarized in Supplementary Table 1. Briefly, 9 patients were found to harbor multiple local failures: 8 patients had 2 lesions, 1 patient, 3 lesions. All patients underwent sRT and no one received androgen deprivation until biochemical failure after SRT. At the time of analysis, median follow up is 27.1 months (IQR: $19.5-33.3$ months).

As shown in Table 1, all patients underwent the $1^{\text {st }}$ repeated DCE-MRI at a median time of 3.3 (IQR: 3.1 4.1) months after treatment completion. Of the patients without a complete response at the $1^{\text {st }}$ reevaluation, 1 was implanted a cardiac device and was unable to undergo further MRI scans. Three more 
patients declined additional testing after the $1^{\text {st }}(\mathrm{N}=2)$ or the $2^{\text {nd }}(\mathrm{N}=1)$ re-evaluation due to issues related to the COVID-19 pandemia.

Regarding the 4 patients lost to re-evaluation before achieving a CR, 3 are biochemically controlled at the last follow up (27.0, 24.5 and 14.1 months after SRT, respectively). The $4^{\text {th }}$ patient had a PSA progression while showing a local PR: the biochemical failure was recorded at 4.23 months after SRT and both reevaluation \#1 (3.67 mths) and \#2 (7.63 mths) revealed a partial response. After the second re-evaluation he was started on androgen deprivation and declined further MRI testing.

\section{Responses}

Responses at each re-evaluation are summarized in Table 1 and illustrated for each patient in Supplementary Figure 1.

Figure 1 shows both the actual and the actuarial cumulative rates of CR. The difference between the two approaches is negligible and for both approaches the median time to CR was identical at 4.7 months (95\% Cl: 3.4-6.0 mths and 3.8-5.6 mths for the actual and the actuarial methods, respectively). Even in the more conservative scenario (actual method), the vast majority $(87.1 \%, 95 \% \mathrm{Cl}: 78.5-94.4 \%)$ of lesions would have completely disappeared by 12 months from the end of sRT.

\section{Predictors of response}

At the first re-evaluation, 33 patients $(53.2 \%, 95 \% \mathrm{Cl}$ : $41.0-65.1 \%)$ were found to be without evidence of local disease. Results of logistic regression on CR at the $1^{\text {st }}$ re-evaluation are summarized in Table 2 . Independent predictors were the volume of the presumed local lesion at pre-sRT MRI and the time elapsed between SRT and the re-evaluation. Due to both missing observations and the limited $(<10)$ number of events at the subsequent re-evaluation time points, no further logistic regression testing was performed.

We categorized baseline lesion volumes at DCE-MRI according to tertiles and the cumulative

incidences of CR in each subgroup are illustrated in Figure 2. All 4 incompletely evaluated lesions belong to the sub-set of lesions larger than $4.5 \mathrm{cc}$ at baseline. Nevertheless, both the actuarial and the actual methods provide identical median times to CR for all sub-groups: 3.6 months (95\%Cl: 3.3-3.8 mths), 4.7 months (95\% Cl: 4.0-5.4 mths) and 6.6 months (95\% Cl: 5.5-7.7 mths) for lesions less than 2cc, between 2 and $4.5 \mathrm{cc}$ and larger than $4.5 \mathrm{cc}$ at diagnosis, respectively. The difference among subgroups is highly significant ( $p=0.009$ and $p=0.003$ according the actuarial and the actual approaches, respectively).

For lesions up to $4.5 \mathrm{cc}$ before sRT we were able to document their complete disappearance by 13 months from the end of treatment (Figure 2). Conversely, out of lesions larger than $4.5 \mathrm{cc}$ only slightly more than $2 / 3$ would have completely disappeared by 12 months $(66.7 \%, 95 \% \mathrm{Cl}: 45.4 \%-82.8 \%$ and $69.6 \%$, $95 \% \mathrm{Cl}: 49.4 \%-89.8 \%$ according to the actual and the actuarial methods, respectively).

\section{Discussion}


About $50 \%$ of patients undergoing RP for localized prostate cancer develop a biochemical failure despite a window of PSA undetectability. While there is some discussion on which PSA threshold best predicts further metastases, both the American and the European Urology as well as Radiation Oncology associations agree to offer 'early' salvage radiotherapy in case of 2 consecutive PSA rises above 0.2 $\mathrm{ng} / \mathrm{ml}(13,14)$. The optimal dose of sRT remains controversial, with $64-66$ Gy at 2 Gy per fraction considered the minimum prescribed dose to the whole prostatic fossa $(14,15)$. However, even if SRT is started at PSA levels below $0.5 \mathrm{ng} / \mathrm{ml}$, up to $50 \%$ of patients harbor one or more visible lesions in the prostatic bed at high resolution DCE-MRI $(9,16,17)$. Though a minority of the detected lesions may be falsely positives $(8,18,19)$ and the detection of a local lesion per se is a favorable prognostic factor $(12$, $16,20)$, there are concerns on the appropriateness of such limited dosages of radiation. Indeed, in a recent randomized trial comparing two dose levels of sRT, local recurrence alone or in combination with other sites represented $21.6 \%$ of all first events of clinical progression after $64 \mathrm{~Gy}$ (1). Moreover, a systematic review showed that each Gy improves the biochemical-free survival after SRT by $2.6 \%$ suggesting that a total dose above $70 \mathrm{~Gy}$ should be administered (21). It has been prospectively shown that local treatment may in turn impact distant metastasis rates in the postoperative setting (22). In order to limit the risk of toxicity associated with dose escalation (14), it seems reasonable to limit the highest prescribed dose level to the site of presumed local disease. We have systematically pursued this strategy in patients undergoing SRT at our institution and here we confirm that the vast majority of local lesions disappears completely after 73.5 Gy in 30 fractions (8).

Prostate cancer response to radiotherapy is monitored usually throughout serum PSA values (23) and little is known on both the clinical/instrumental response rate of prostate cancer along with its timing after radiotherapy $(8,24)$. Pilepich and Hederman in the post-radiation evaluation of 262 patients in the pre-PSA era showed CR rates at 12 months similar to those reported in Figure 1 with smaller primary tumors regressing somewhat faster than larger ones at digital rectal exam (25).

While DCE-MRI, and in particular changes in apparent diffusion coefficient, have been used to assess the response of prostate cancer to primary radiotherapy $(26,27)$, the post-RP/pre-sRT setting is different due to the lack of normal prostate tissue surrounding the lesion and the presence of anatomical changes due to surgery (28). Though in previously untreated prostate cancer the diagnostic role of DCE-MRI is marginal (29), it represents the most important sequence in the detection of recurrent disease after RP (30) since recurrent tumor neo-angiogenesis is composed by disorganized and permeable blood vessels that result in an early hyper-intense focal lesion (28). Even if early radiation-induced changes may actually increase vessel permeability and thus potentially increase tumor flare (28), successful radiotherapy leads to fibrosis and decreased blood flow/permeability that has been associated with pathologically complete responses in various cancer sub-sites (31-34).

We have found that SRT is highly effective in obtaining the complete resolution of local lesions. Interestingly, response was found to be a time-dependent process even within the same re-evaluation window (Table 2) and, as shown in Figure 1, assessment of response at DCE-MRI should be deferred several months after sRT end. Moreover, despite DCE is a functional test, we found the lesion volume to 
be the only additional independent predictor of response at multivariable analysis. Surprisingly, none of the factors potentially correlated with tumor aggressiveness (i.e. Gleason score) were found to predict the timing of response. On the other hand, microvessel density, that is a surrogate of angiogenesis, has been inconsistently correlated to pathologic tumor stage and Gleason score in prostate cancer (35). Limitations of the present study include the fact that the time interval of re-evaluation was delayed by a few months due to issues related to the COVID-19 pandemia (Table 1). In particular, the $3^{\text {rd }}$ re-evaluation took place on average at 10.7 months instead of 9 months, even if this has minimal impact on the interpretation of the results (Figure 1). More importantly, 4 (6.4\%) patients were lost before achieving a CR and this prevents us to draw firm conclusions on the long term response of larger lesions. However, the cumulative incidence for lesions larger than $4.5 \mathrm{cc}$ are quite similar up to 12 months regardless the method used for computation of rates, suggesting that until this time point results are not impacted by censoring. Moreover, as discussed elsewhere (9), we assumed all detected local lesions to be prostate cancer-related at baseline despite an estimated rate of false positives for multiparametric MR up to $10 \%$ $(18,36)$. Therefore, the goal of $100 \%$ for the cumulative incidence of CR might be unrealistic in absence of a baseline positive biopsy though false positive lesions usually remain unchanged after SRT as discussed elsewhere (8).

\section{Conclusion}

The present prospective study documents the complete dis-appearance of the vast majority of presumed local lesions after dose-escalated sRT though this requires several months after treatment completion. The timing of $\mathrm{CR}$ is at least in part predictable based on the volume of the lesion with smaller lesions responding quicker and within $\approx 1$ year from treatment end.

\section{Declarations}

Ethics approval and consent to participate: The study was conducted according to the guidelines of the Declaration of Helsinki and approved by the Ethics Committee of the 'Regina Elena' National Cancer Institute (protocol code 946/17) and approved 13 June 2017.

Consent for publication: Informed consent was obtained from all subjects involved in the study.

Data availability: https://gbox.garr.it/garrbox/index.php/s/aJGRXorlc8ItRFy.

Competing interests: The authors declare that they have no competing interests.

Funding: The author(s) received no specific funding for this work.

Authors' contribution: conceptualization G.S., methodology G.S. and D.G., software, V.L., D.G. and G.S., validation, A.F. (Adriana Faiella), A.F. (Alessia Farneti), P.D. and L.B., formal analysis, D.G., investigation, G.S., P.V., resources, A.F. (Adriana Faiella), data curation, A.F. (Adriana Faiella) and M.B., writing-original 
draft preparation, G.S. and M.B., writing-review and editing, L.B. and M.B., supervision, G.S. All authors have read and agreed to the published version of the manuscript.

Acknowledgments: Not applicable.

\section{References}

1. Ghadjar P, Hayoz S, Bernhard J, Zwahlen DR, Holscher T, Gut P, et al. Dose-intensified Versus Conventional-dose Salvage Radiotherapy for Biochemically Recurrent Prostate Cancer After Prostatectomy: The SAKK 09/10 Randomized Phase 3 Trial. European urology. 2021,80(3):306-15.

2. Carrie C, Magne N, Burban-Provost P, Sargos P, Latorzeff I, Lagrange JL, et al. Short-term androgen deprivation therapy combined with radiotherapy as salvage treatment after radical prostatectomy for prostate cancer (GETUG-AFU 16): a 112-month follow-up of a phase 3, randomised trial. The Lancet Oncology. 2019,20(12):1740-9.

3. Yokomizo A, Wakabayashi M, Satoh T, Hashine K, Inoue T, Fujimoto K, et al. Salvage Radiotherapy Versus Hormone Therapy for Prostate-specific Antigen Failure After Radical Prostatectomy: A Randomised, Multicentre, Open-label, Phase 3 Trial (JCOG0401)(dagger). European urology. 2020,77(6):689-98.

4. Parker CC, Clarke NW, Cook AD, Kynaston HG, Petersen PM, Catton C, et al. Timing of radiotherapy after radical prostatectomy (RADICALS-RT): a randomised, controlled phase 3 trial. Lancet. 2020,396(10260):1413-21.

5. Sargos P, Chabaud S, Latorzeff I, Magne N, Benyoucef A, Supiot S, et al. Adjuvant radiotherapy versus early salvage radiotherapy plus short-term androgen deprivation therapy in men with localised prostate cancer after radical prostatectomy (GETUG-AFU 17): a randomised, phase 3 trial. The Lancet Oncology. 2020,21(10):1341-52.

6. Cox JD, Gallagher MJ, Hammond EH, Kaplan RS, Schellhammer PF. Consensus statements on radiation therapy of prostate cancer: guidelines for prostate re-biopsy after radiation and for radiation therapy with rising prostate-specific antigen levels after radical prostatectomy. American Society for Therapeutic Radiology and Oncology Consensus Panel. Journal of clinical oncology : official journal of the American Society of Clinical Oncology. 1999,17(4):1155.

7. Beresford MJ, Gillatt D, Benson RJ, Ajithkumar T. A systematic review of the role of imaging before salvage radiotherapy for post-prostatectomy biochemical recurrence. Clinical oncology. 2010,22(1):46-55.

8. Sanguineti G, Bertini L, Faiella A, Ferriero MC, Marzi S, Farneti A, et al. Response on DCE-MRI predicts outcome of salvage radiotherapy for local recurrence after radical prostatectomy. Tumori. 2021,107(1):55-63.

9. Faiella A, Sciuto R, Giannarelli D, Bottero M, Farneti A, Bertini L, et al. A Prospective Study Assessing the Post-Prostatectomy Detection Rate of a Presumed Local Failure at mpMR with Either (64) $\mathrm{CuCl} 2$ or (64)CuPSMA PET/CT. Cancers (Basel). 2021,13(21). 
10. Connolly JA, Shinohara K, Presti JC, Jr., Carroll PR. Local recurrence after radical prostatectomy: characteristics in size, location, and relationship to prostate-specific antigen and surgical margins. Urology. 1996,47(2):225-31.

11. Masi M, Landoni V, Faiella A, Farneti A, Marzi S, Guerrisi M, et al. Comparison of rigid and deformable coregistration between mpMRI and CT images in radiotherapy of prostate bed cancer recurrence. Phys Med. 2021,92:32-9.

12. Sharma V, Nehra A, Colicchia M, Westerman ME, Kawashima A, Froemming AT, et al. Multiparametric Magnetic Resonance Imaging Is an Independent Predictor of Salvage Radiotherapy Outcomes After Radical Prostatectomy. European urology. 2018,73(6):879-87.

13. Thompson IM, Valicenti RK, Albertsen P, Davis BJ, Goldenberg SL, Hahn C, et al. Adjuvant and salvage radiotherapy after prostatectomy: AUA/ASTRO Guideline. The Journal of urology. 2013,190(2):441-9.

14. Cornford $P$, van den Bergh RCN, Briers E, Van den Broeck T, Cumberbatch MG, De Santis M, et al. EAUEANM-ESTRO-ESUR-SIOG Guidelines on Prostate Cancer. Part II-2020 Update: Treatment of Relapsing and Metastatic Prostate Cancer. European urology. 2021,79(2):263-82.

15. Schaeffer E, Srinivas S, Antonarakis ES, Armstrong AJ, Bekelman JE, Cheng H, et al. NCCN Guidelines Insights: Prostate Cancer, Version 1.2021. Journal of the National Comprehensive Cancer Network: JNCCN. 2021,19(2):134-43.

16. Breen WG, Stish BJ, Harmsen WS, Froemming AT, Mynderse LA, Choo CR, et al. The prognostic value, sensitivity, and specificity of multiparametric magnetic resonance imaging before salvage radiotherapy for prostate cancer. Radiotherapy and oncology : journal of the European Society for Therapeutic Radiology and Oncology. 2021,161:9-15.

17. Coppola A, Platania G, Ticca C, De Mattia C, Bortolato B, Palazzi MF, et al. Sensitivity of CE-MRI in detecting local recurrence after radical prostatectomy. La Radiologia medica. 2020,125(7):683-90.

18. Panebianco V, Sciarra A, Lisi D, Galati F, Buonocore V, Catalano C, et al. Prostate cancer: 1HMRSDCEMR at $3 T$ versus $[(18) F]$ choline PET/CT in the detection of local prostate cancer recurrence in men with biochemical progression after radical retropubic prostatectomy (RRP). European journal of radiology. 2012,81(4):700-8.

19. Liauw SL, Pitroda SP, Eggener SE, Stadler WM, Pelizzari CA, Vannier MW, et al. Evaluation of the prostate bed for local recurrence after radical prostatectomy using endorectal magnetic resonance imaging. International journal of radiation oncology, biology, physics. 2013,85(2):378-84.

20. Emmett L, van Leeuwen PJ, Nandurkar R, Scheltema MJ, Cusick T, Hruby G, et al. Treatment Outcomes from (68)Ga-PSMA PET/CT-Informed Salvage Radiation Treatment in Men with Rising PSA After Radical Prostatectomy: Prognostic Value of a Negative PSMA PET. Journal of nuclear medicine : official publication, Society of Nuclear Medicine. 2017,58(12):1972-6.

21. King CR. The dose-response of salvage radiotherapy following radical prostatectomy: A systematic review and meta-analysis. Radiotherapy and oncology : journal of the European Society for Therapeutic Radiology and Oncology. 2016,121(2):199-203. 
22. Swanson GP, Hussey MA, Tangen CM, Chin J, Messing E, Canby-Hagino E, et al. Predominant treatment failure in postprostatectomy patients is local: analysis of patterns of treatment failure in SWOG 8794. Journal of clinical oncology : official journal of the American Society of Clinical Oncology. 2007,25(16):2225-9.

23. Roach M, 3rd, Hanks G, Thames H, Jr., Schellhammer P, Shipley WU, Sokol GH, et al. Defining biochemical failure following radiotherapy with or without hormonal therapy in men with clinically localized prostate cancer: recommendations of the RTOG-ASTRO Phoenix Consensus Conference. International journal of radiation oncology, biology, physics. 2006,65(4):965-74.

24. Rischke HC, Schafer AO, Nestle U, Volegova-Neher N, Henne K, Benz MR, et al. Detection of local recurrent prostate cancer after radical prostatectomy in terms of salvage radiotherapy using dynamic contrast enhanced-MRI without endorectal coil. Radiation oncology. 2012,7:185.

25. Pilepich MV, Hederman MA. Prognostic significance of the pattern of tumor regression following definitive radiotherapy for carcinoma of the prostate. American journal of clinical oncology. 1986,9(6):494-9.

26. Pasquier D, Hadj Henni A, Escande A, Tresch E, Reynaert N, Colot O, et al. Diffusion weighted MRI as an early predictor of tumor response to hypofractionated stereotactic boost for prostate cancer. Sci Rep. 2018,8(1):10407.

27. Song I, Kim CK, Park BK, Park W. Assessment of response to radiotherapy for prostate cancer: value of diffusion-weighted MRI at 3 T. AJR Am J Roentgenol. 2010,194(6):W477-82.

28. Berman RM, Brown AM, Chang SD, Sankineni S, Kadakia M, Wood BJ, et al. DCE MRI of prostate cancer. Abdominal radiology. 2016,41(5):844-53.

29. Schwartz LH, Litiere S, de Vries E, Ford R, Gwyther S, Mandrekar S, et al. RECIST 1.1-Update and clarification: From the RECIST committee. European journal of cancer. 2016,62:132-7.

30. Casciani E, Polettini E, Carmenini E, Floriani I, Masselli G, Bertini L, et al. Endorectal and dynamic contrast-enhanced MRI for detection of local recurrence after radical prostatectomy. AJR Am J Roentgenol. 2008,190(5):1187-92.

31. Huang YS, Chen JL, Hsu FM, Huang JY, Ko WC, Chen YC, et al. Response assessment of stereotactic body radiation therapy using dynamic contrast-enhanced integrated MR-PET in non-small cell lung cancer patients. Journal of magnetic resonance imaging : JMRI. 2018,47(1):191-9.

32. Spratt DE, Arevalo-Perez J, Leeman JE, Gerber NK, Folkert M, Taunk NK, et al. Early magnetic resonance imaging biomarkers to predict local control after high dose stereotactic body radiotherapy for patients with sarcoma spine metastases. The spine journal : official journal of the North American Spine Society. 2016,16(3):291-8.

33. Taunk NK, Oh JH, Shukla-Dave A, Beal K, Vachha B, Holodny A, et al. Early posttreatment assessment of MRI perfusion biomarkers can predict long-term response of lung cancer brain metastases to stereotactic radiosurgery. Neuro-oncology. 2018,20(4):567-75.

34. George ML, Dzik-Jurasz AS, Padhani AR, Brown G, Tait DM, Eccles SA, et al. Non-invasive methods of assessing angiogenesis and their value in predicting response to treatment in colorectal cancer. The 
British journal of surgery. 2001,88(12):1628-36.

35. Taverna G, Grizzi F, Colombo P, Graziotti PP. Microvessel density estimate: friend or foe in the light of prostate vascular system complexity? World journal of urology. 2010,28(3):405-6.

36. Sanguineti G, Bertini L, Faiella A, Ferriero MC, Marzi S, Farneti A, et al. Response on DCE-MRI predicts outcome of salvage radiotherapy for local recurrence after radical prostatectomy. Tumori. 2020:300891620908950.

\section{Tables}

Table 1. Summary of findings at rDCE-MRI.

\begin{tabular}{|c|c|c|c|c|c|c|c|}
\hline & A & B & $A-B$ & & & & \\
\hline $\begin{array}{l}\text { Re- } \\
\text { ev } \\
\#\end{array}$ & $\begin{array}{l}\text { Patients } \\
\text { due for } \\
\text { scanning }\end{array}$ & $\begin{array}{l}\text { noCR not } \\
\text { further } \\
\text { evaluated }\end{array}$ & $\begin{array}{l}\text { \# patients } \\
\text { actually } \\
\text { scanned }\end{array}$ & $\begin{array}{l}\text { Median time } \\
\text { (mths) of } \\
\text { scan after } \\
\text { sRT (IQR) }\end{array}$ & $\begin{array}{l}\text { Complete } \\
\text { Response }\end{array}$ & $\begin{array}{l}\text { No } \\
\text { Response }\end{array}$ & $\begin{array}{l}\text { Partial } \\
\text { Response }\end{array}$ \\
\hline & (\#) & (\#) & $(\#)$ & (months) & (\#) & $(\#)$ & $(\#)$ \\
\hline $1^{\text {st }}$ & 62 & 0 & 62 & $3.3(3.1-4.1)$ & 33 & 2 & 27 \\
\hline $2^{\text {nd }}$ & 29 & 1 & 28 & $6.8(6.5-7.6)$ & 20 & 0 & 8 \\
\hline $3^{\text {rd }}$ & 9 & 3 & 6 & $\begin{array}{l}10.7(10.6- \\
12.6)\end{array}$ & 4 & 0 & 2 \\
\hline $4^{\text {th }}$ & 5 & 4 & 1 & 16.7 & 1 & 0 & 0 \\
\hline
\end{tabular}

Abbreviations: Re-ev: re-evaluation

Table 2. Logistic Regression on CR at $1^{\text {st }}$ re-evaluation 


\begin{tabular}{|c|c|c|c|c|c|c|c|c|}
\hline \multirow[b]{2}{*}{ Covariate } & \multirow[b]{2}{*}{ Strata } & \multirow[b]{2}{*}{$\begin{array}{l}\# \\
\text { patients }\end{array}$} & \multicolumn{3}{|c|}{ Univariable } & \multicolumn{3}{|c|}{ Multivariable } \\
\hline & & & OR & $95 \% \mathrm{Cl}$ & $\begin{array}{l}p \\
\text { value }\end{array}$ & OR & $95 \% \mathrm{Cl}$ & $\begin{array}{l}\mathrm{p} \\
\text { value }\end{array}$ \\
\hline $\begin{array}{l}\text { Volume @ } \\
\text { baseline MRI (cc) }\end{array}$ & Continuum & 62 & 0.207 & $\begin{array}{l}0.045- \\
0.958\end{array}$ & 0.044 & 0.076 & $\begin{array}{l}0.009- \\
0.667\end{array}$ & 0.020 \\
\hline PSADT (mths) & Continuum & 62 & 0.977 & $\begin{array}{l}0.948- \\
1.006\end{array}$ & 0.120 & & & \\
\hline PSA@ fail (ng/ml) & Continuum & 62 & 0.843 & $\begin{array}{l}0.558- \\
1.274\end{array}$ & 0.418 & & & \\
\hline \multirow{2}{*}{$\begin{array}{l}\text { Site failure } \\
\text { Anastomosis }\end{array}$} & No & 25 & 1 & & & & & \\
\hline & Yes & 37 & 1.422 & $\begin{array}{l}0.513- \\
3.940\end{array}$ & 0.498 & & & \\
\hline \multirow{2}{*}{$\begin{array}{l}\text { Site failure Bladder } \\
\text { Neck }\end{array}$} & No & 45 & 1 & & & & & \\
\hline & Yes & 17 & 0.512 & $\begin{array}{l}0.165- \\
1.588\end{array}$ & 0.246 & & & \\
\hline \multirow{2}{*}{$\begin{array}{l}\text { Site failure } \\
\text { Retrovesical }\end{array}$} & No & 47 & 1 & & & & & \\
\hline & Yes & 15 & 1.437 & $\begin{array}{l}0.441- \\
4.682\end{array}$ & 0.547 & & & \\
\hline $\begin{array}{l}\text { Time RP/sRT } \\
\text { (mths) }\end{array}$ & Continuum & 62 & 0.991 & $\begin{array}{l}0.980- \\
1.002\end{array}$ & 0.117 & & & \\
\hline \multirow[t]{3}{*}{ GGG } & $1-2$ & 29 & 1 & & & & & \\
\hline & 3 & 25 & 0.880 & $\begin{array}{l}0.301- \\
2.574\end{array}$ & 0.816 & & & \\
\hline & $4-5$ & 8 & 0.813 & $\begin{array}{l}0.169- \\
3.895\end{array}$ & 0.795 & & & \\
\hline $\begin{array}{l}\text { Time from sRT } \\
\text { (mths) }\end{array}$ & Continuum & 62 & 2.472 & $\begin{array}{l}1.050- \\
5.818\end{array}$ & 0.038 & 3.399 & $\begin{array}{l}1.156- \\
9.993\end{array}$ & 0.026 \\
\hline $\begin{array}{l}\text { PSA decrease @ } \\
\text { wk } 5(\%)\end{array}$ & Continuum & 62 & 1.026 & $\begin{array}{l}1.003- \\
1.049\end{array}$ & 0.024 & 1.025 & $\begin{array}{l}0.999- \\
1.050\end{array}$ & 0.058 \\
\hline $\begin{array}{l}\text { PSA decrease @ } \\
1^{\text {st }} \text { ev (\%) }\end{array}$ & Continuum & 62 & 1.025 & $\begin{array}{l}0.998- \\
1.052\end{array}$ & 0.067 & & & \\
\hline \multirow[t]{2}{*}{ \# Failures } & 1 & 53 & 1 & & & & & \\
\hline & $2-3$ & 9 & 1.116 & $\begin{array}{l}0.269- \\
4.622\end{array}$ & 0.880 & & & \\
\hline Pelvic node & No & 33 & 1 & & & & & \\
\hline
\end{tabular}



Yes
29
0.893
$0.328-$
2.427
0.824

Figures

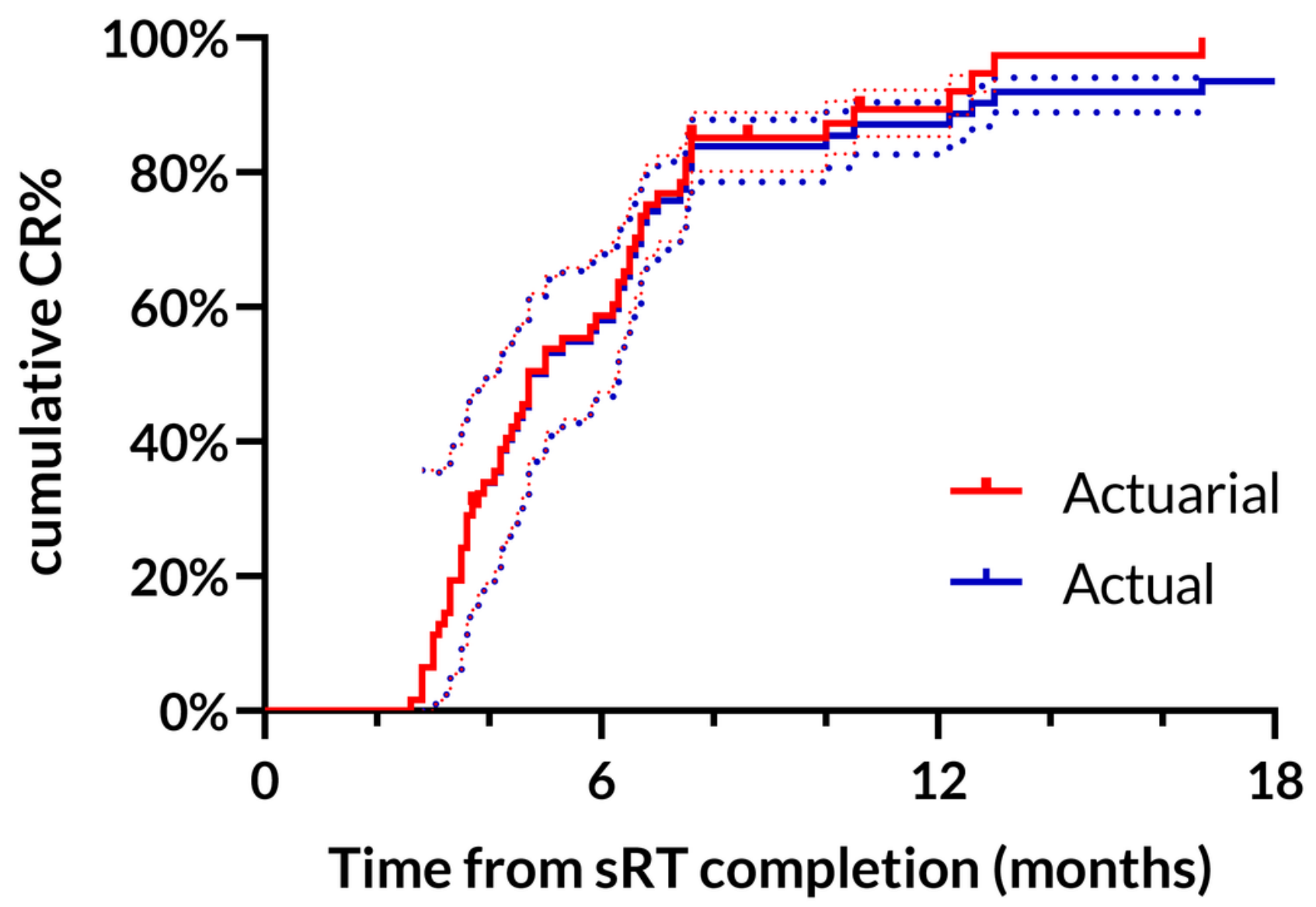

\# pts at risk 62

25

26

4

0

8

4

Figure 1

Estimated cumulative incidence rates $(95 \% \mathrm{Cl})$ of $\mathrm{CR}$ after SRT. The actuarial method (red line) censors for the 4 patients who were lost to follow up before achieving a CR while the actual method (blue line) treats lost observations as persisting incomplete responses. 


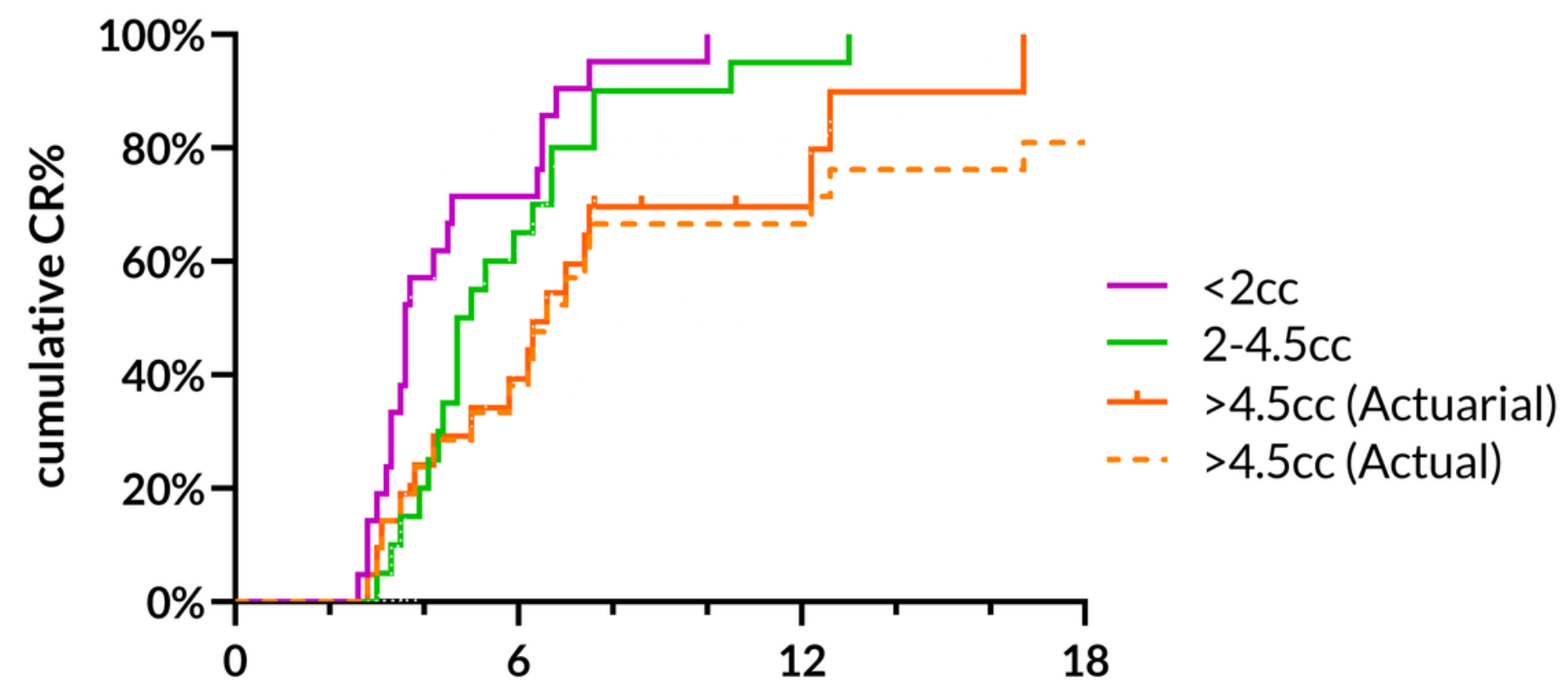

Time from sRT completion (months)

$\begin{array}{lrrrr}\text { \# pts at risk } & 21 & 6 & 0 & 0 \\ & 20 & 7 & 1 & 0 \\ & 21 & 12 & 3 & 0\end{array}$

\section{Figure 2}

Estimated cumulative incidence rates $(95 \% \mathrm{Cl})$ of $\mathrm{CR}$ by baseline volume at DCE-MRI. For lesions up to $4.5 \mathrm{cc}$, both the actuarial and the actual methods provide identical results since there are no censored observations: for lesions larger than $4.5 \mathrm{cc}$, both approaches (actuarial, solid line and actual, dashed line) are shown. The difference among both actuarial and actual curves is highly significant $(p=0.009$ and $p=0.003$ for the former and the latter ones, respectively).

\section{Supplementary Files}

This is a list of supplementary files associated with this preprint. Click to download.

- SupplementaryMaterial.docx 